\section{HELPING YOU DESIGN YOUR PERFECT SURGERY}

A-dec knows that choosing new surgery equipment is one of the most important decisions that you will make within your career as a dental professional, and with it comes the opportunity for you to enhance and improve the whole way in which you practise dentistry. You may want to increase productivity, reduce clutter or simply create a relaxed yet efficient and healthy environment for the benefit of the dental team and patient experience.

To complement great equipment, $\mathrm{A}$-dec have a network of highly trained authorised equipment specialists throughout the UK and Republic of Ireland to help plan and implement your perfect surgery design and provide subsequent service and support. A-dec's dealers are there to walk you through the entire project from start to finish covering all aspects from safety issues through to optimum use of space to meet your individual needs.

Telephone 0800233285.

\section{GIVING INFANTS THE BEST START POSSIBLE}

To help give children the best start possible, recommend Spry Toothgel with Xylitol for the perfect way to keep dental cavities at bay.

Xylitol is a naturally occurring sweetener that is proven to be a powerful tool in the fight against tooth decay. Thanks to its unique chemical composition, xylitol is unfavourable to the metabolism of plaque bacteria, reducing their ability to proliferate and adhere. This makes xylitol an excellent tool in the fight against dental caries

Available in a handy $60 \mathrm{ml}$ tube, Spry Toothgel is a great way to introduce children to oral hygiene and comes in a number of child-friendly flavours to make teeth cleaning even more fun.

Based on all-natural ingredients, Spry Toothgel is completely safe for infants - it is safe to swallow and fluoride-free. For the very young, Spry Toothgel can be used to gently massage into gums and teeth or can be used in conjunction with Spry Baby Banana Brush as the ideal introduction to regular brushing.

For further information contact Anyone 4 Tea Ltd on 01428 652131, or visit www.anyone4tea. com.

\title{
HIGHLY EFFICIENT YET COMPACT AUTOCLAVE
}

The new Alpha autoclave from Prestige Medical has been designed to offer dental practices an extremely affordable sterilisation solution.

If you are looking for a cost effective means of sterilising your instruments, Alpha sets high standards for speed, efficiency and performance. Highly efficient, yet compact, its capacity to process six full sized trays is twice as many as its nearest rivals. So, if you're a busy practice, this capacity to cope with heavy demands saves you valuable time and reduces your operating costs.

A 16 litre ' $N$ ' class non-vacuum autoclave, Alpha includes both $121^{\circ} \mathrm{C}$ and $134^{\circ} \mathrm{C}$ cycles with a drying option. It is supplied complete with three trays, your choice of printer or data logger and comes with a full one-year warranty.

Alpha is made in the UK by Prestige Medical and will be installed and commissioned by an engineer who will also train your staff on how to use it - all completely free of charge.

More information is available by calling 01254844103 , emailing sales@prestigemedical.co.uk or visiting www.prestigemedical.co.uk/uk/dentistry.

\section{BETTER BRUSHING AND MOTIVATION PACKS}

Aquafresh understands the importance of good oral care habits from an early age. As well as an oral care range suitable for every stage in a child's development, engaging packaging designs and age appropriate toothpaste formulations, the brand supports the education of younger patients and their carers through the provision of Aquafresh Kids Motivation Packs to dental surgeries. Now Aquafresh is expanding this initiative to encourage better brushing in the community, as well as in practice, with the 'Better Brushing Programme'.

The 'Better Brushing Programme' is designed to support the fantastic work dental professionals and their teams are doing with local oral health

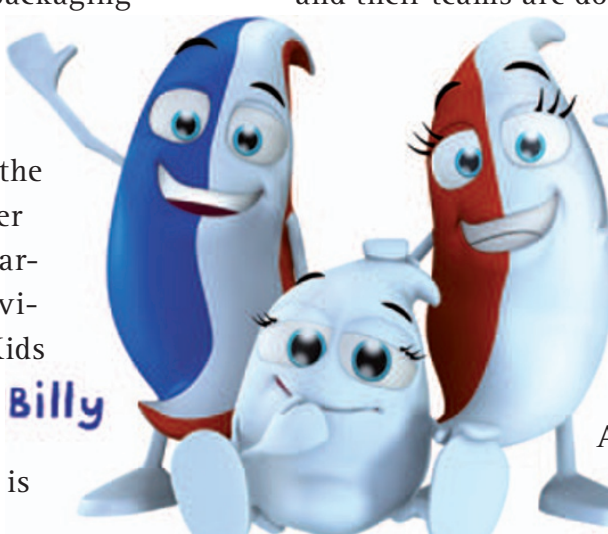

initiatives, through the provision of educational materials and

In addition to this new initiative, GlaxoSmithKline Consumer Healthcare has refreshed the products within the Aquafresh kids range. The Aquafresh Kids toothproduct samples. paste range is staged by age to contain the appropriate level of fluoride in line with Department of Health guidelines and a mint taste profile which is designed to help children progress to the flavour of adult toothpaste. Aquafresh My Big Teeth Mouthwash is for children age $6+$ and is available in two flavours. Aquafresh children's toothbrushes feature new packaging and appealing designs. The brand is also launching a new teether to extend the oral care they provide to babies as well as children.

www.gsk-dentalprofessionals. co.uk 